This is the author's final, peer-reviewed manuscript as accepted for publication. The publisher-formatted version may be available through the publisher's web site or your institution's library.

\title{
Effect of curing temperature and glass type on the pozzolanic reactivity of glass powder.
}

Mohammadreza Mirzahosseini, Kyle A. Riding

\section{How to cite this manuscript}

If you make reference to this version of the manuscript, use the following information:

Mirzahosseini, M., \& Riding, K. A. (2014). Effect of curing temperature and glass type on the pozzolanic reactivity of glass powder. Retrieved from http://krex.ksu.edu.

\section{Published Version Information}

Citation: Mirzahosseini, M., \& Riding, K. A. (2014). Effect of curing temperature and glass type on the pozzolanic reactivity of glass powder. Cement and Concrete Research, 58, 103-111.

Copyright: (c) 2014 Elsevier Ltd.

Digital Object Identifier (DOI):10.1016/j.cemconres.2014.01.015

Publisher's Link: http://dx.doi.org/10.1016/j.cemconres.2014.01.015

This item was retrieved from the K-State Research Exchange (K-REx), the institutional repository of Kansas State University. K-REx is available at http://krex.ksu.edu 


\title{
Effect of Curing Temperature and Glass Type on the Pozzolanic Reactivity of Glass Powder

\author{
Mohammadreza Mirzahosseini ${ }^{1}$, Kyle A. Riding ${ }^{1}$
}

\begin{abstract}
Glass cullet has been considered for use in concrete as a fine aggregate or a supplementary cementitious material (SCM). Glass reaction kinetics depends on both temperature and glass composition. Uniform composition, amorphous nature, and high silica content of glass make it ideal for studying effects of glass type on reactivity at different temperatures. In this study, the pozzolanicity of clear and green glass crushed smaller than $25 \mu \mathrm{m}$ at three different temperatures (i.e. $10^{\circ} \mathrm{C}, 23^{\circ} \mathrm{C}$, and $50^{\circ} \mathrm{C}$ ) was measured using isothermal calorimetry, chemical shrinkage, and thermogravimetric analysis. Additionally, mortar compressive strength and water absorption of samples at different temperatures and ages have been used to relate reaction degree to performance. Results indicate that elevated temperatures cause glass powder to exhibit significant pozzolanic reaction, even at early ages. Moreover, glass composition was seen to have a large impact on reactivity. In this study, green glass showed higher reactivity than clear glass.
\end{abstract}

Keywords: Glass cullet; Pozzolanic reactivity; Degree of hydration; Hydration rate; Elevated temperature

${ }^{1}$ Department of Civil Engineering, Kansas State University, Manhattan, KS 66506, United States 


\section{Introduction}

Millions of tons of glass cullet are landfilled throughout the world every year. In 2005, approximately 12.8 million tons of glass cullet was landfilled in the United States [1]. When waste glass is collected, different color glass is often intermixed. Mixed color glass cannot be recycled, however, because a mixing of coloring agents results in an unpredictable and uncontrollable color in the new glass. Machines are capable of using optical sensors to efficiently sort large glass pieces by color; however, sorting small glass pieces is not economical and much of this unrecyclable glass cullet is then landfilled. For instance, every year 1.65 million tons of waste glasses are disposed in the U.K. because of unsuitability for recycling [2]. As the economic and environmental consequences of landfilling rise, the incentive to reuse glass cullet has grown. The concrete industry is one of the potential ways of reusing millions of tons of glass cullet per year either as aggregate or supplementary cementitious material (SCM).

Most research on crushed glass has focused on the use of glass as fine aggregates in concrete. However, durability concerns over alkali-silica reaction (ASR) have limited the use of glass as a fine aggregate replacement in concrete [3]. Several studies have shown that glass behaves pozzolanically if ground finely enough, with a surface area of more than $300 \mathrm{~m}^{2} / \mathrm{kg}$ [4-9]. The pozzolanic reaction occurs between amorphous silica in the SCM, calcium hydroxide $(\mathrm{CH})$ as a byproduct of the cement reaction, and water to form additional calcium silicate hydrate. Most studies on the effect of glass cullet on cementitious mixtures as SCM focused on mechanical and durability properties. Increases in long term compressive strength, flexural strength, resistance to ASR and sulfate attack, and reduction in water sorptivity of concrete containing finely ground glass powder have been found [10-11]. Moreover, some studies showed that finely ground glass powder had comparable or slightly better mechanical properties at later ages than fly ash and slag, but much less than silica fume [12-13]. Despite all aforementioned results, few studies have 
aimed to connect the microstructural properties of cementitious mixture containing glass powder to performance characteristics of the glass mixtures. Federico [14] performed extensive study on the influence of glass powder on kinetic and performance properties of cementitious mixtures. However, the effect of curing temperatures on different types of glass cullet reaction kinetics and performance has not been studied.

Temperature is one of the most pivotal parameters which affect cement or cementitious material hydration. Concrete temperature can change due to weather, heat curing applied, and heat of hydration. Elevated temperatures can increase the rate of hydration, early strength gain, change hydration products formed, change density of the formed products, and accelerate activation of pozzolanic activity [15-16]. However, high temperatures can also lower ultimate strength, increase permeability and drying shrinkage, and in some cases, cause delayed ettringite formation (DEF) [17,15].

This study focuses on quantifying the kinetic reactivity of very finely ground glass particles (finer than $25 \mu \mathrm{m}$ ) in concrete as partial cement replacement at different isothermal temperatures, namely $10^{\circ} \mathrm{C}, 23^{\circ} \mathrm{C}$, and $50^{\circ} \mathrm{C}$ with performance as measured by strength and sorptivity.

\section{Experimental Program}

\subsection{Materials}

An ordinary portland cement type I/II was utilized for the current study and distilled water was used for the mixing water. Table 1 summarizes the chemical properties of the portland cement obtained by X-ray fluorescence (XRF) analysis. Table 2 shows the potential compositions of the cement based on Bogue equations. 
Table 1. Chemical components of cementitious materials

\begin{tabular}{lcccccccc}
\hline \multirow{2}{*}{ Cementitious Materials } & \multicolumn{7}{c}{ Chemical Components } \\
\cline { 2 - 8 } & $\mathrm{SiO}_{2}(\%)$ & $\mathrm{Al}_{2} \mathrm{O}_{3}(\%)$ & $\mathrm{CaO}(\%)$ & $\mathrm{Na}_{2} \mathrm{O}(\%)$ & $\mathrm{K}_{2} \mathrm{O}(\%)$ & $\mathrm{Cr}_{2} \mathrm{O}_{3}(\%)$ & $\mathrm{Fe}_{2} \mathrm{O}_{3}(\%)$ & $\mathrm{CaCO}_{3}(\%)$ \\
\hline OPC & 19.66 & 4.71 & 62.74 & 0.12 & 0.56 & - & 3.26 & 2.2 \\
Clear Glass & 73.50 & 0.06 & 9.02 & 12.65 & 0.02 & 0.02 & 0.28 & - \\
Green Glass & 73.10 & 1.65 & 10.55 & 12.34 & 0.58 & 0.24 & 0.44 & - \\
\hline
\end{tabular}

Table 2. Potential composition of cement based on Bogue equations

\begin{tabular}{cccc}
\hline $\mathrm{C}_{3} \mathrm{~S}(\%)$ & $\mathrm{C}_{2} \mathrm{~S}(\%)$ & $\mathrm{C}_{3} \mathrm{~A}(\%)$ & $\mathrm{C}_{4} \mathrm{AF}(\%)$ \\
\hline 58 & 11 & 7 & 10 \\
\hline
\end{tabular}

Clear and green glass was used in this study because previous research results showed that clear glass is the most commonly available type of glass and green glass has the highest pozzolanic reaction. Small impurities are added as coloring agent in glass production. These coloring agents change the glass composition and structure. The source of clear glass was waste window glass collected from recycling company at Kansas City, KS, and the source of green glass was bottle glass from the same bottle manufacturer and bottle type collected from recycling center in Manhattan, KS. The glass was washed and dried to remove any residues before crushing. After crushing to smaller than $1.18 \mathrm{~mm}$ (No. 16), glass particles were milled in a laboratory ball mill. After ball milling, the glass was wet-sieved using a sieve with $25 \mu \mathrm{m}$ openings and isopropanol. The chemical compositions of the glass powders used for this study are shown in Table 1, while Table 3 shows glass powder density and Blaine fineness. Glass powder and cement particle size distribution is shown in Figure 1, demonstrating that the gradation of glass powder is very similar to the cement gradation. Particle shape and texture of cement grain and glass particles was investigated by scanning electronic microscopy (SEM), as shown in Figure 2. 
Table 3. Density and Blaine surface area of cementitious materials

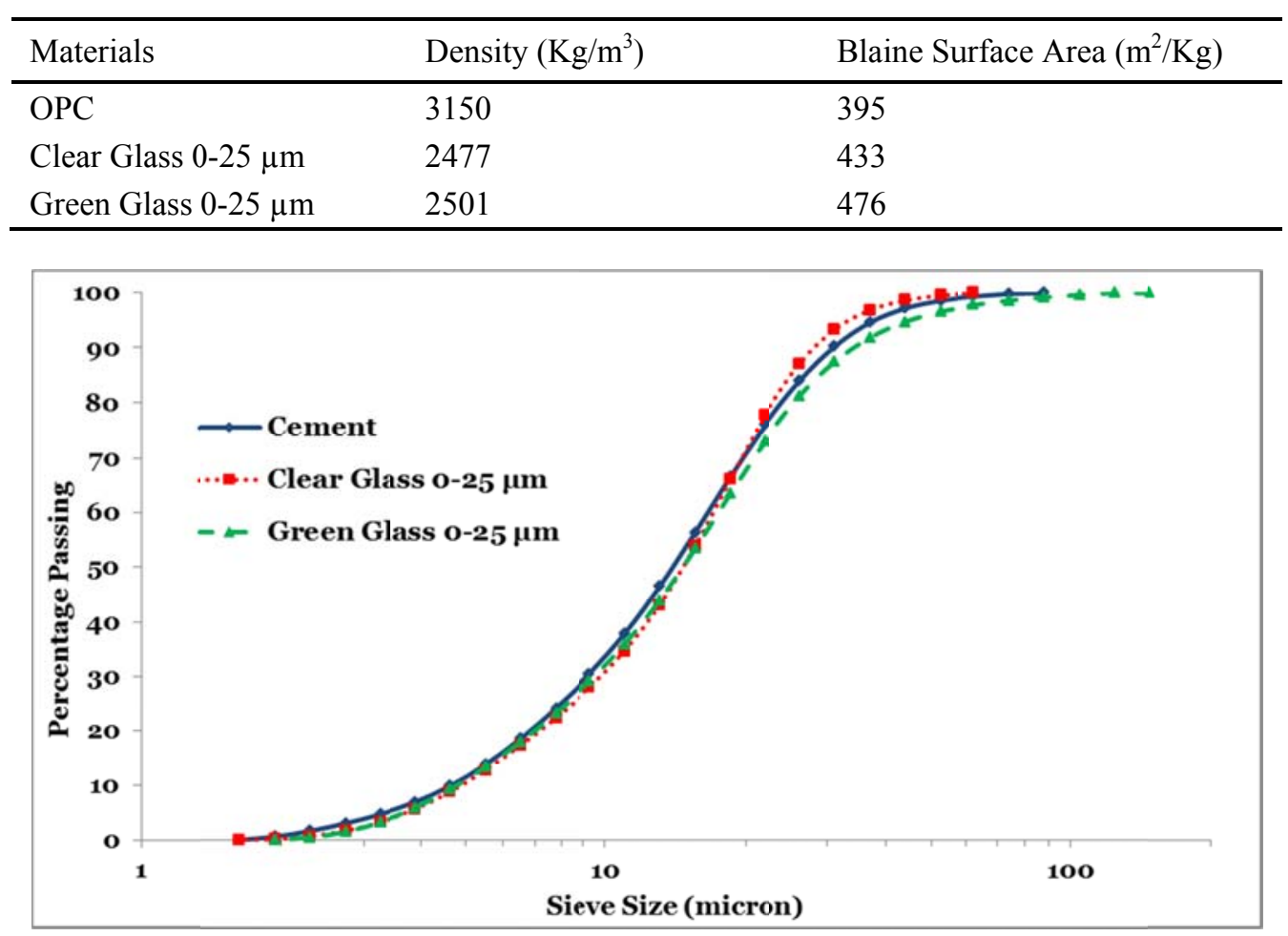

Figure 1. Gradation of cementitious materials

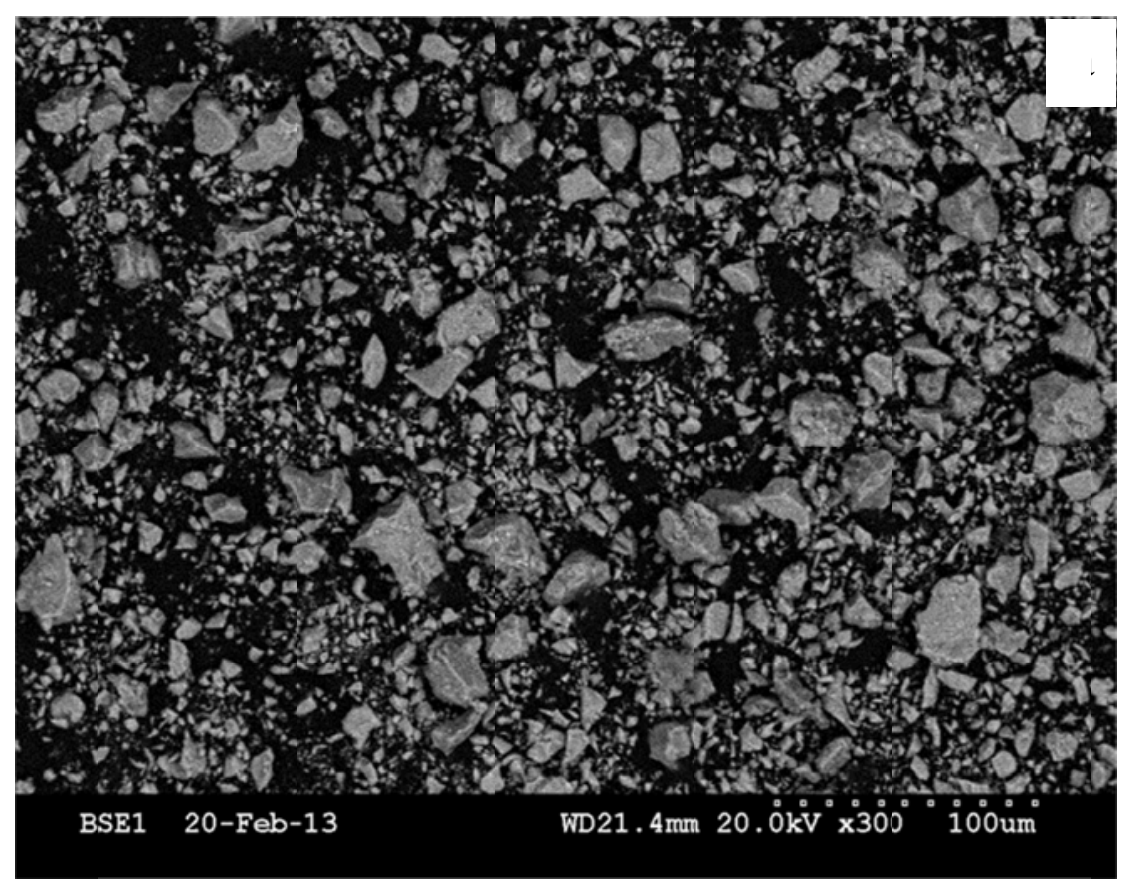




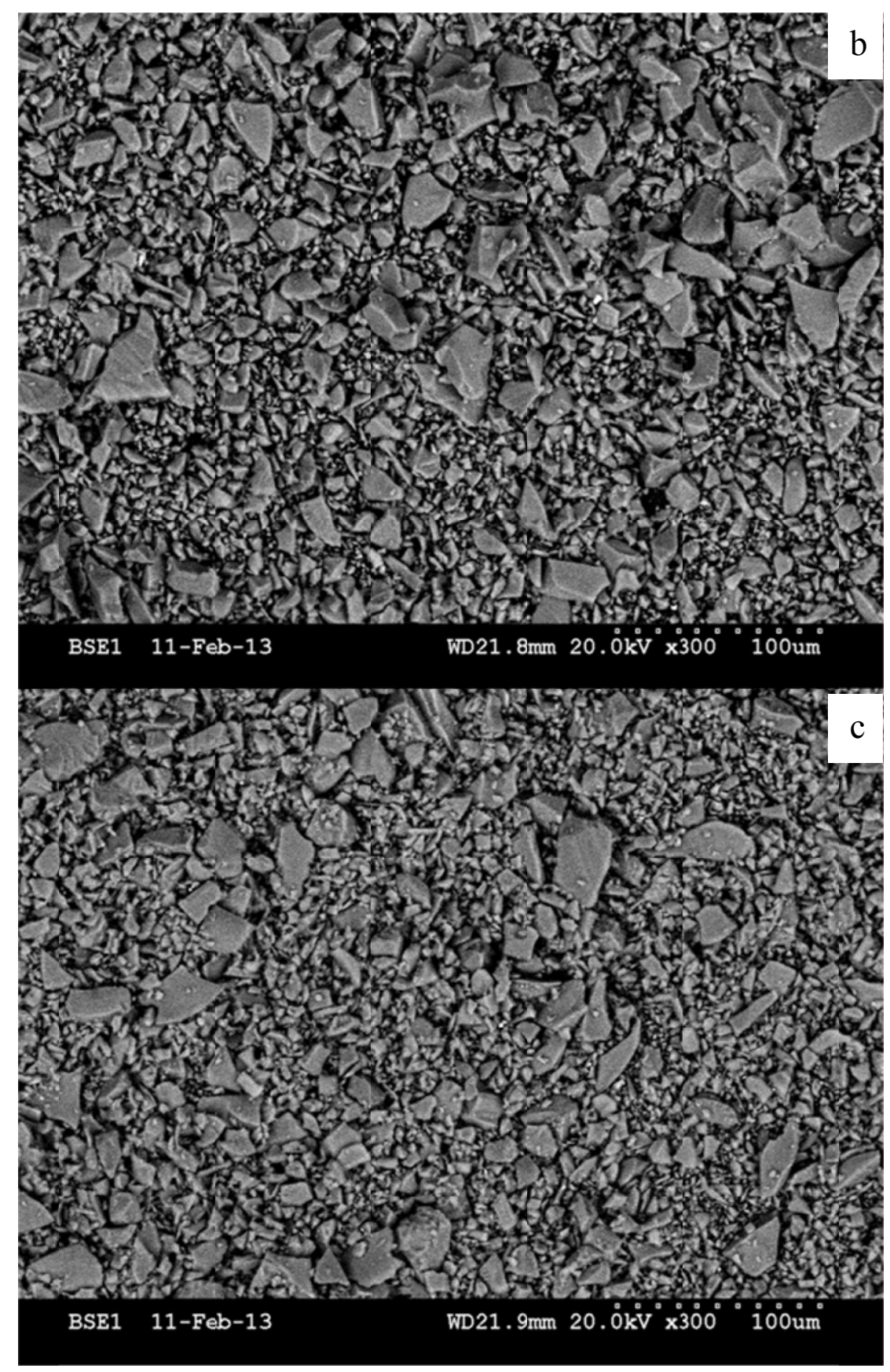

Figure 2. SEM Images; a. Cement grain, b. Clear glass 0-25 $\mu \mathrm{m}$, c. Green glass 0-25 $\mu \mathrm{m}$

\subsection{Methodology}

\subsubsection{Bottle Leaching}

Bottle leaching experiments were carried out to measure concentration of aluminum and silica ions that leach out into alkaline solutions at different $\mathrm{pH}$ values. In the bottle leaching, five 
grams of glass powder with different types and sizes was poured into 50 grams of potassium hydroxide $(\mathrm{KOH})$ solution with $\mathrm{pH}$ varying from 12 to 14.5 . This variation in $\mathrm{pH}$ of $\mathrm{KOH}$ solution was obtained by adding different amounts of $\mathrm{KOH}$ to ultrapure water until the target $\mathrm{pH}$ was achieved. The solution was rotated at $30 \pm 1 \mathrm{rpm}$ for $24 \mathrm{~h}$ and filtered. Inductively Coupled Plasma (ICP) Spectrometry was used to measure ion concentrations.

\subsubsection{Cement Paste Experiments}

Cement paste samples were made with a water-cementitious materials ratio of 0.35 , using a $25 \%$ replacement by mass of portland cement with clear or green glass powder. All materials were preconditioned at target temperatures $\left(10^{\circ} \mathrm{C}, 23^{\circ} \mathrm{C}\right.$, and $\left.50^{\circ} \mathrm{C}\right)$ before mixing. The mixing procedure combined water and cementitious materials at $500 \mathrm{rpm}$ for three minutes, followed by two minutes rest, and finally, mixing at $2000 \mathrm{rpm}$ for two minutes. After mixing, paste samples for thermogravimetric analysis (TGA) and SEM were casted in a polystyrene vials with diameter of $17 \mathrm{~mm}$ and height of $50 \mathrm{~mm}$. Paste samples with or without the glass powder were wet-cured beginning at six hours after casting at three curing temperatures in a temperature-controlled chamber.

The cementitious system heat of hydration rate was measured using an eight-channel isothermal calorimeter. Approximately 30 gr of paste samples were placed in calorimetry cups, and the cups were immediately placed into calorimetry channels. The time between initial contact of water and cementitious materials and placing samples into the calorimeter was less than $15 \mathrm{~min}$ in all cases. The influences of glass type and curing temperatures on hydration kinetics could be observed as the change in heat of hydration when the calorimetry results were normalized by the mass of dry portland cement used in the paste. This change in the heat of hydration in the mixtures containing glass compared to the control mixture shows changes in system reaction [18-19]. The apparent activation energy concept describes the temperature 
sensitivity of physical and chemical properties of different cementitious mixtures [13]. For cementitious systems where multiple chemical reactions occur simultaneously, the Arrhenius concept does not yield true activation energy but provides a parameter for temperature sensitivity of overall reaction rate useful for modeling [20]. Eq. (1) shows the mathematical form of the apparent activation energy [21]:

$\mathrm{K}(\mathrm{T})=\mathrm{A} \mathrm{e}^{-\mathrm{E} / \mathrm{RT}}$

Where $\mathrm{K}(\mathrm{T})$ is the rate constant, $\mathrm{T}$ is absolute temperature, $\mathrm{A}$ is proportionality constant, $\mathrm{E}_{\mathrm{a}}$ is apparent activation energy of concrete $(\mathrm{J} / \mathrm{mol})$, and $\mathrm{R}$ is universal gas constant $(8.314 \mathrm{~J} / \mathrm{mol} \mathrm{K})$. The hydration rate can then be presented by Eq. (2) [21]:

$\frac{d \alpha}{d t}=g(\alpha) \times K(T)$ Eq. (2)

Where $\alpha$ is degree of hydration, $g(\alpha)$ is the function of the degree of hydration. The apparent activation energy was also calculated based on the Arrhenius plot according to the procedure described by Poole et al. [20].

Chemical shrinkage was used as a complementary method to calorimetry for measuring the cementitious system reaction rate. Chemical shrinkage is especially suited for measuring reaction rate after the heat of hydration drops too low to be measured by the isothermal calorimeter. Chemical shrinkage measurements in the current study were performed according to ASTM C 1608 [22]. This method involved placing cement paste in a vial, covering it with water, tightly inserting a rubber stopper into the vial, and placing a drop of red oil on top of the water raised through a pipette. The cementitious system volume change was measured through image analysis (IA) of pictures automatically taken of a drop of colored petrol on top of the water in the filled capillary tube. The software for image analysis was developed by Bishnoi [23]. 
A pozzolanic reaction between $\mathrm{CH}$ and glass cullet can be responsible for the strength increase in concrete. The $\mathrm{CH}$ content of cement paste samples was determined by thermogravimetric analysis (TGA) using the approach outlined by Marsh [24]. Paste samples with or without the glass powder were wet-cured beginning at $6 \mathrm{~h}$ after casting at three curing temperatures. At 1, 7, 28, and 91 days after casting, hydration was stopped by solvent exchange with isopropanol. Paste samples were cut from the 17-mm diameter samples into $2 \mathrm{~mm}$ thick discs and placed in isopropanol for seven days. Samples were then dried in a vacuum for four to five days, ground to fine powder, and heated in a nitrogen rich atmosphere in a TGA at $20^{\circ} \mathrm{C} / \mathrm{min}$ up to $1000^{\circ} \mathrm{C}$.

Scanning electron microscopy (SEM) was performed on cut and polished paste discs, after solvent exchange and drying in a vacuum to examine any differences in microstructure. Thirty SEM images were taken in backscattered mode (BSE) from each paste disc containing glass powder at a given curing age and curing temperatures. In backscattered mode (BSE) of SEM, image brightness is a function of the material average atomic number and can be used to differentiate between different phases in the image [25]. In particular, C-S-H relative brightness was used to measure change in C-S-H relative density and effect of temperature on C-S-H density [26]. C-S-H density was calculated using the approach described by Zhang [27].

\subsubsection{Cement Mortar Samples}

All mortar mixtures used in this study were made with a water-to-cementitious material ratio $(w / \mathrm{cm})$ of 0.485 and sand to cementitious material $(\mathrm{s} / \mathrm{cm})$ of 2.75 specified by ASTM C 109 [28]. The $w / \mathrm{cm}$ of mortar samples is different from that for paste samples because of bleeding issues found in paste samples at high $\mathrm{w} / \mathrm{cm}$ ratio and workability problems in mortar samples with lower w/cm. Mortar samples were made with and without glass powders using a $25 \%$ cement replacement by mass. Mortar samples were cured at $10^{\circ} \mathrm{C}, 23^{\circ} \mathrm{C}$, and $50^{\circ} \mathrm{C}$. 
Fifty $\mathrm{mm}$ mortar cubes were made and tested at 1, 7, 28, and 91 days after mixing for compressive strength. Compressive strength of mortar cubes was performed according to ASTM C 109 [28] as a measure of pozzolanic reaction of the glass particle with time. Compressive strength at each age is reported as the average of compressive strength results of three mortar cubes.

Durability of concrete is strongly impacted by concrete water and ion transport properties. A comparison between strength and water sorptivity of mortar provides information in regards to pore connectivity and tortuosity because compressive strength is a function of pore volume [29]. Water sorptivity is also dependent on pore volume but additionally dependent on pore size distribution, connectivity, and tortuosity. Cylinders with $75 \mathrm{~mm}$ diameter by $150 \mathrm{~mm}$ height were casted for water sorptivity tests. Water sorptivity was measured using the procedure outlined by ASTM C 1585 and modified by Zhang [30, 27]. Samples were sawcut at the same ages as compressive strength testing to $30 \mathrm{~mm}$ thick for use in a water sorptivity test. After sawcutting, three samples for each age were placed in isopropanol to stop hydration by solvent exchange. Following seven days in isopropanol, the samples were dried in a vacuum for seven days and weighed. The top and sides of the disc samples were sealed with plastic and waterproof tape, leaving the bottom side exposed to water. The samples were then placed in water so that $2 \pm 1 \mathrm{~mm}$ from the bottom of the disc was submerged. The mortar discs were taken out of the water; the sample bottom was blotted with a paper towel to remove free surface water and weighed. The procedure was repeated at regular intervals until eight days [27].

\section{Results and Discussions}

\subsection{Leaching}

Based on the bottle leaching test (Figure 3), green glass has more silica and aluminum ion in solution at higher $\mathrm{pH}$ (i.e. more than 12.5), meaning that changes in green glass microstructure, 
which was caused by adding impurities to give color to glass, as well as breakdown of silica framework by high $\mathrm{pH}$ resulted in higher dissolution rate of green glass. Thus, green glass may react faster because aluminum and silica of the green glass are more easily and quickly dissolved in cement matrix [31].

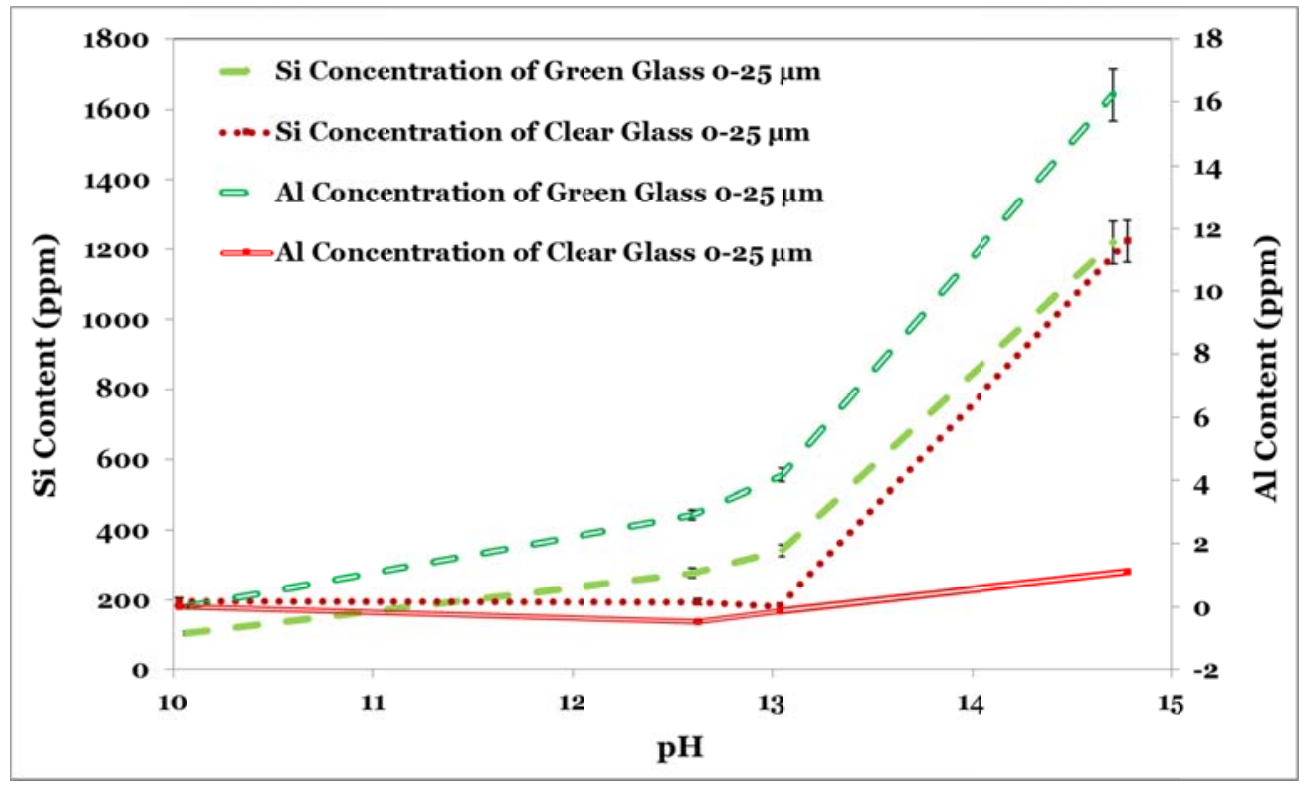

Figure 3. Al and Si concentrations at different pH (ICP test)

\subsection{Isothermal calorimetry}

Figure 4 shows total heat of hydration for control samples and samples containing clear and green glass of $0-25 \mu \mathrm{m}$ hydrated at $10^{\circ} \mathrm{C}, 23^{\circ} \mathrm{C}$, and $50^{\circ} \mathrm{C}$. As seen in the figure, the total heat of hydration at 96 hours at $10^{\circ} \mathrm{C}$ and $23^{\circ} \mathrm{C}$ temperature is similar for both types of glass, meaning the degree of cement hydration at 96 hours is the similar for clear and green glass samples. At $50^{\circ} \mathrm{C}$, green glass showed $10 \%$ higher total heat of hydration compared to clear glass, reflecting the higher reactivity of green glass at elevated temperatures. However, glass samples show slightly higher total hydration heats than control samples at all temperatures (i.e. 12\%, 13.5\%, and $20 \%$ at $10^{\circ} \mathrm{C}, 23^{\circ} \mathrm{C}$, and $50^{\circ} \mathrm{C}$, respectively). At lower temperatures, i.e. $10^{\circ} \mathrm{C}$ and $23^{\circ} \mathrm{C}$, the increase in heat of hydration rate of samples containing glass particles is most likely the result of 
greater space availability from increased effective $w / \mathrm{cm}$. While at $50^{\circ} \mathrm{C}$, the increase in hydration rate is mostly caused by combination of higher effective w/cm and glass particle pozzolanic reaction, which was evidenced by higher reaction rate of green glass compared to clear glass at $50^{\circ} \mathrm{C}$.

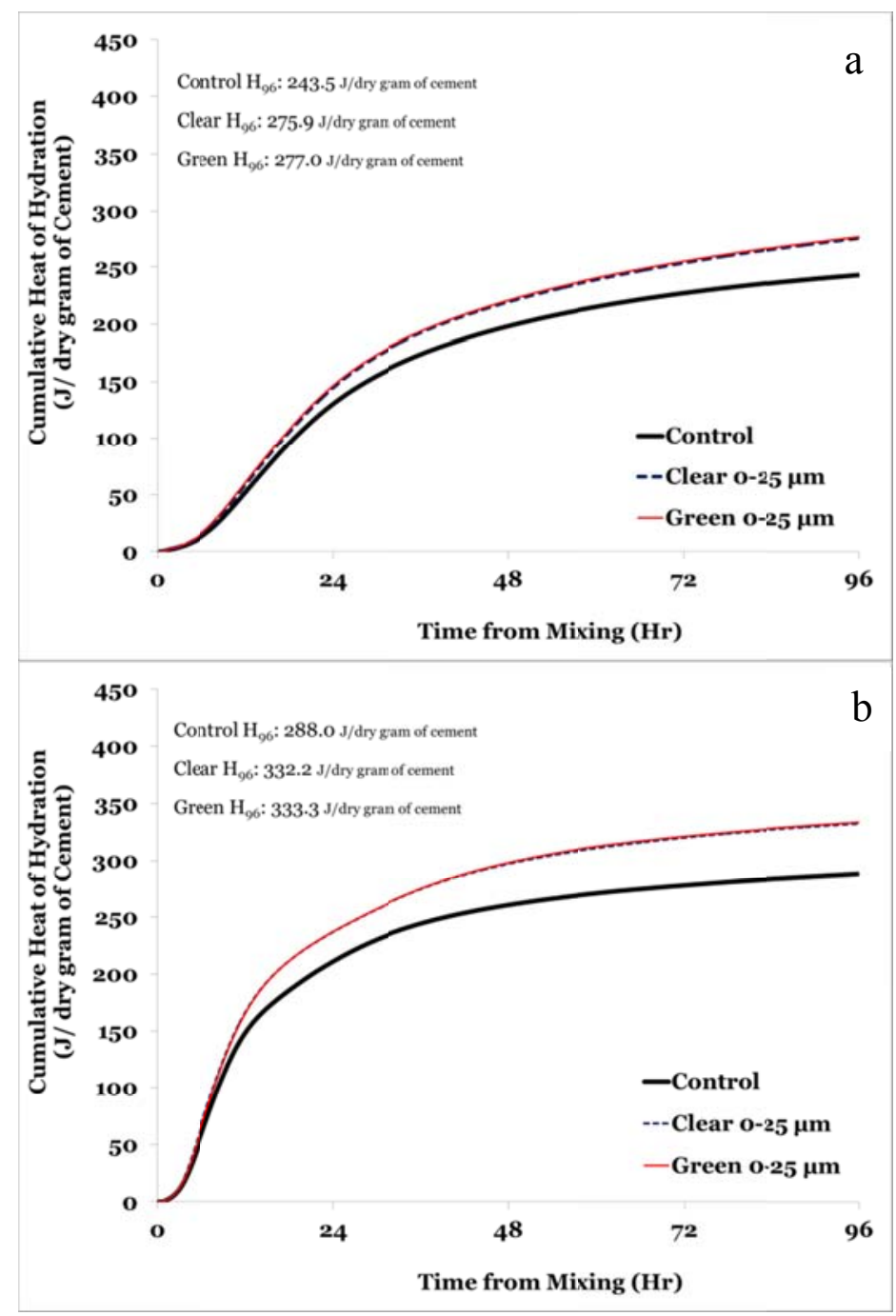




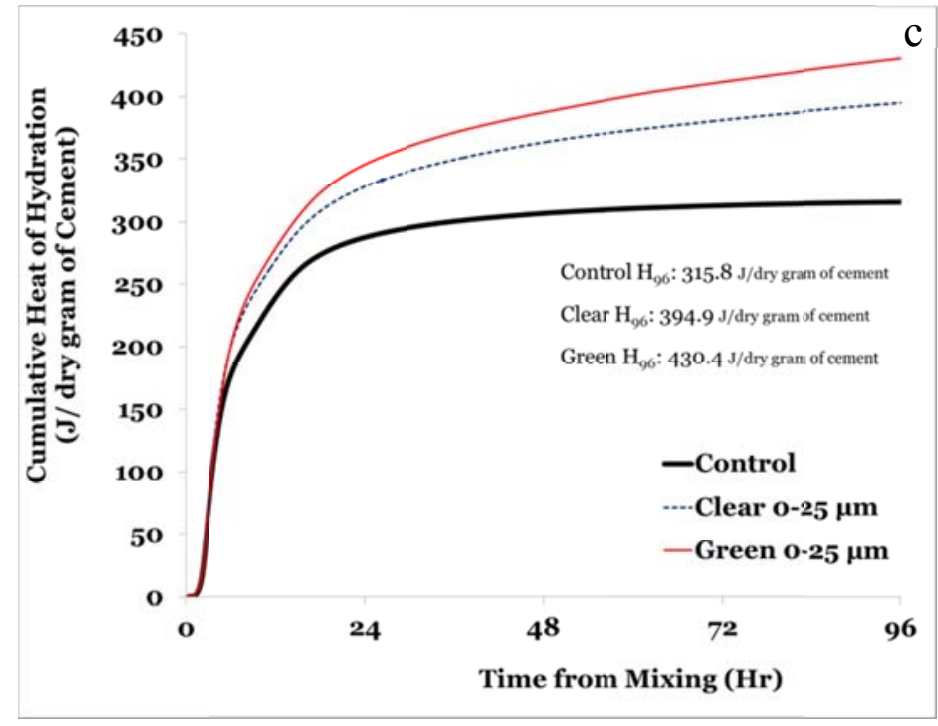

Figure 4. Total heat of hydration of paste samples; a. at $10^{\circ} \mathrm{C}$, b. at $23^{\circ} \mathrm{C}$, c. at $50^{\circ} \mathrm{C}$

The Arrhenius plot of control samples and samples containing glass powder is shown in Figure 5. While control samples and clear glass samples have similar $\mathrm{E}_{\mathrm{a}}$ (i.e. 38.2 and 37.0, respectively), the green glass sample has slightly higher apparent activation energy (i.e. 9\%$12 \%$ ) than the other two mixtures [20], indicating that green glass is more sensitive to temperature and more reactive at elevated temperatures than clear glass.

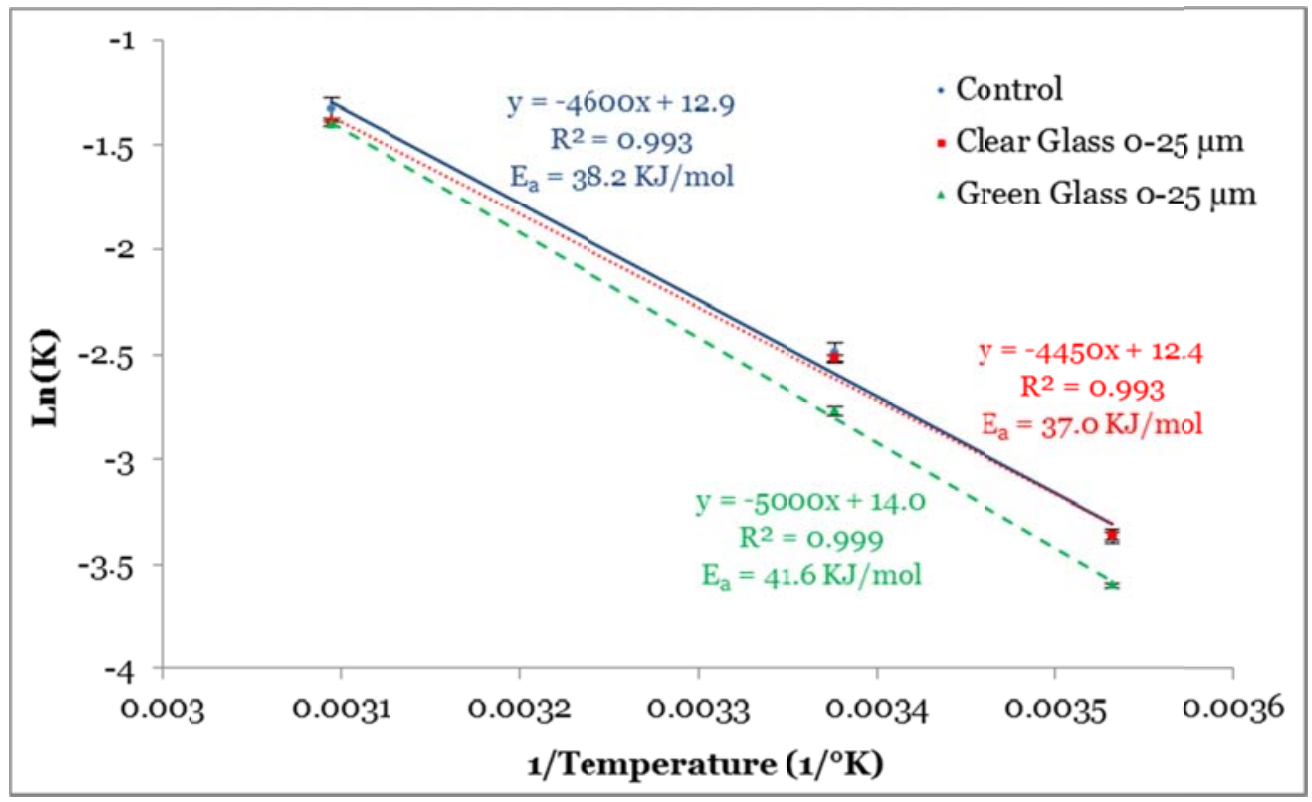

Figure 5. Arrhenius plot of cementitious samples 


\subsection{Chemical shrinkage}

Figure 6 depicts chemical shrinkage results through 28 days of hydration for control samples and samples containing glass powder at $10^{\circ} \mathrm{C}, 23^{\circ} \mathrm{C}$, and $50^{\circ} \mathrm{C}$. As was seen in heat of hydration measurements, increased temperature greatly increased reaction rate, as measured by chemical shrinkage. Furthermore, pastes made with clear and green glass show different reactivity at all temperatures, unlike the calorimetry results. At $10^{\circ} \mathrm{C}$, clear glass sample showed $31 \%$ higher chemical shrinkage than control samples at 28 days, while green glass powder showed an increase in reactivity at 28 days of $48 \%$ compared to the control samples. Increases in reactivity at $50^{\circ} \mathrm{C}$ compared to $10^{\circ} \mathrm{C}$ are $14.5 \%, 46 \%$, and $22.5 \%$ for control, clear glass, and green glass samples, respectively. These results not only reveal that green glass is likely more reactive than clear glass, but the effect of curing temperature could also be taken into account. Higher chemical shrinkage measurements which show a higher amount of reaction at $50^{\circ} \mathrm{C}$ shows the great influence of elevated temperatures on cement and glass hydration.

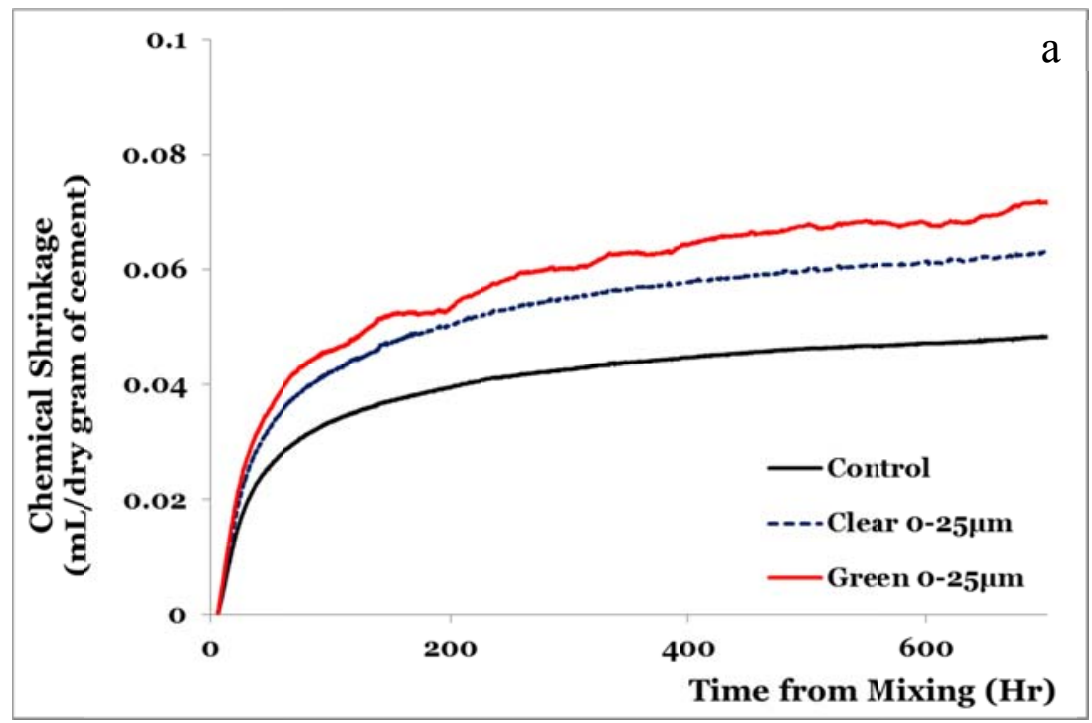




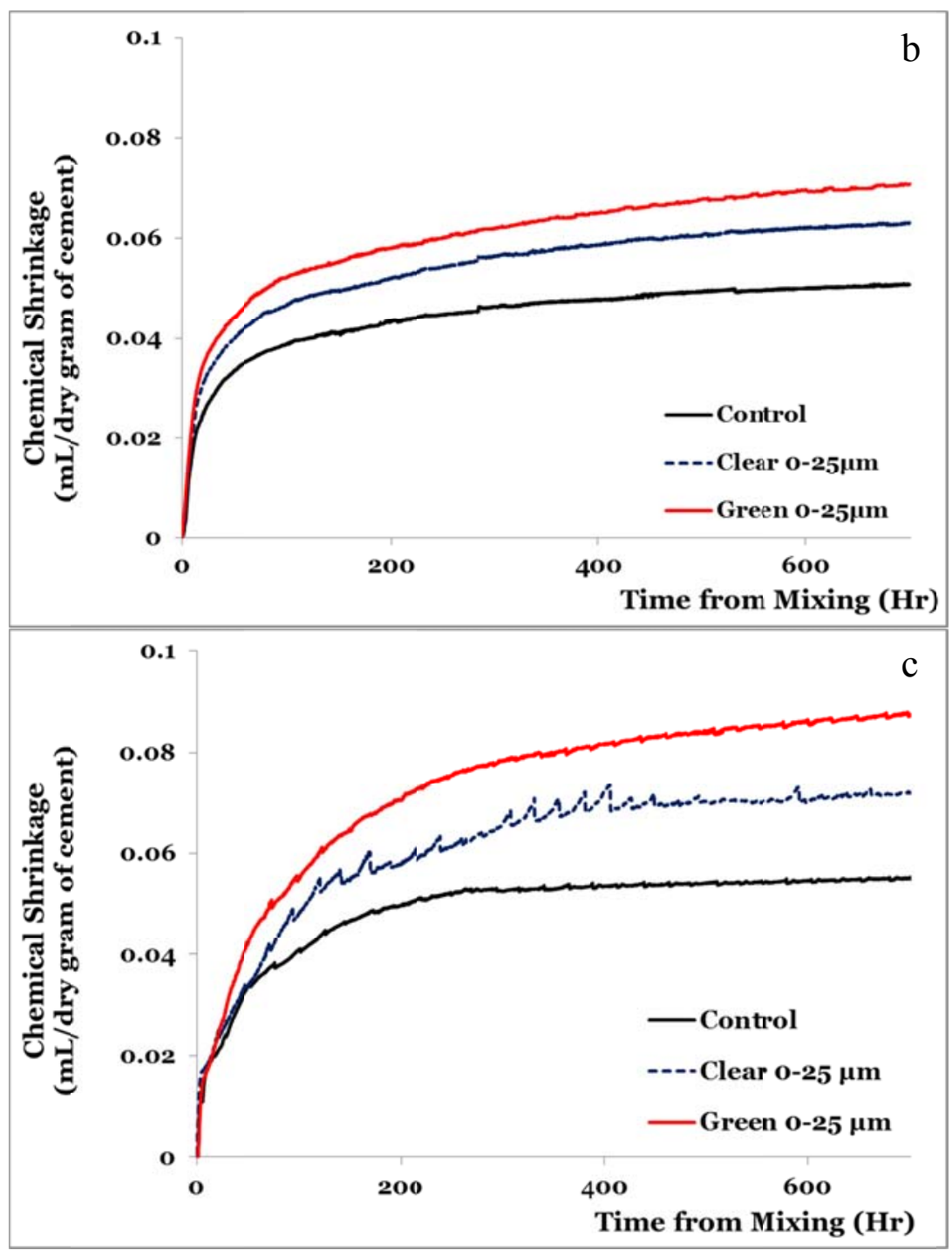

Figure 6. Chemical shrinkage of paste samples; a. at $10^{\circ} \mathrm{C}$, b. at $23^{\circ} \mathrm{C}$, c. at $50^{\circ} \mathrm{C}$

\subsection{Thermogravimetric Analysis (TGA)}

Change in $\mathrm{CH}$ content with time and curing temperature in cement paste samples is shown in Figure 7. At the low temperature $\left(10^{\circ} \mathrm{C}\right)$, the decrease in $\mathrm{CH}$ seen with time as an indication of the pozzolanic reaction was not seen to be significant. However, at $23^{\circ} \mathrm{C}$, samples with green glass powder had about 13\%, 18\%, and 19\% lower $\mathrm{CH}$ than control samples at 7, 28, and 91 days, respectively. Glass powder showed significant long-term $\mathrm{CH}$ reaction at $50^{\circ} \mathrm{C}$ : samples with clear and green glass of $0-25 \mu \mathrm{m}$ showed $9 \%$ reduction in $\mathrm{CH}$ even at one day. At seven 
days, clear and green glasses showed $\mathrm{CH}$ reduction of $13 \%$ and 23\%, respectively. At 28 and 91 days, clear and green glass samples behaved similarly since both can lower $\mathrm{CH}$ content by approximately $34 \%$, confirming that elevated temperatures can accelerate the glass hydration reaction.

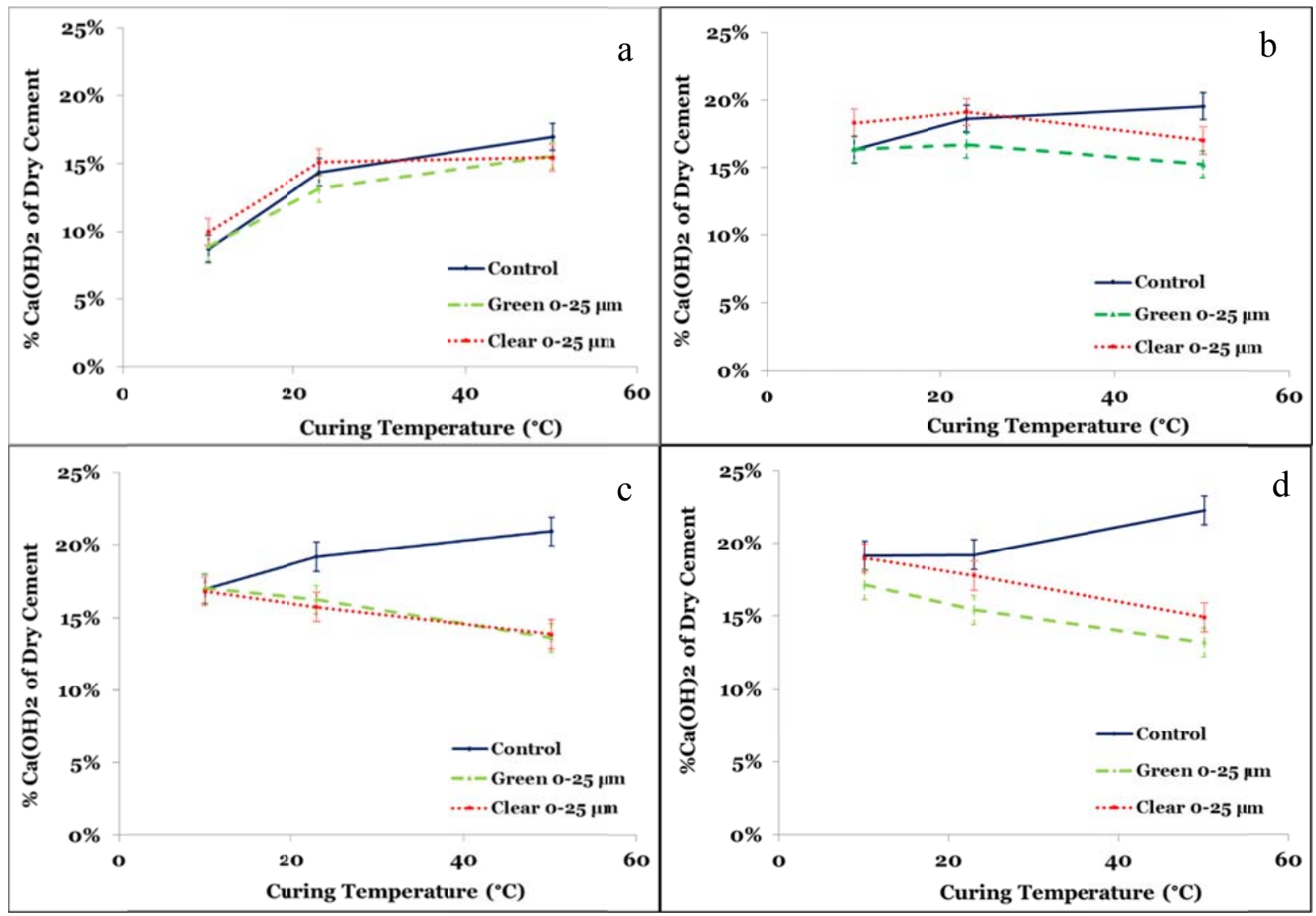

Figure 7. CH content of paste samples; a. at 1 day, b. at 7 days, c. at 28 days, d. at 91 days 

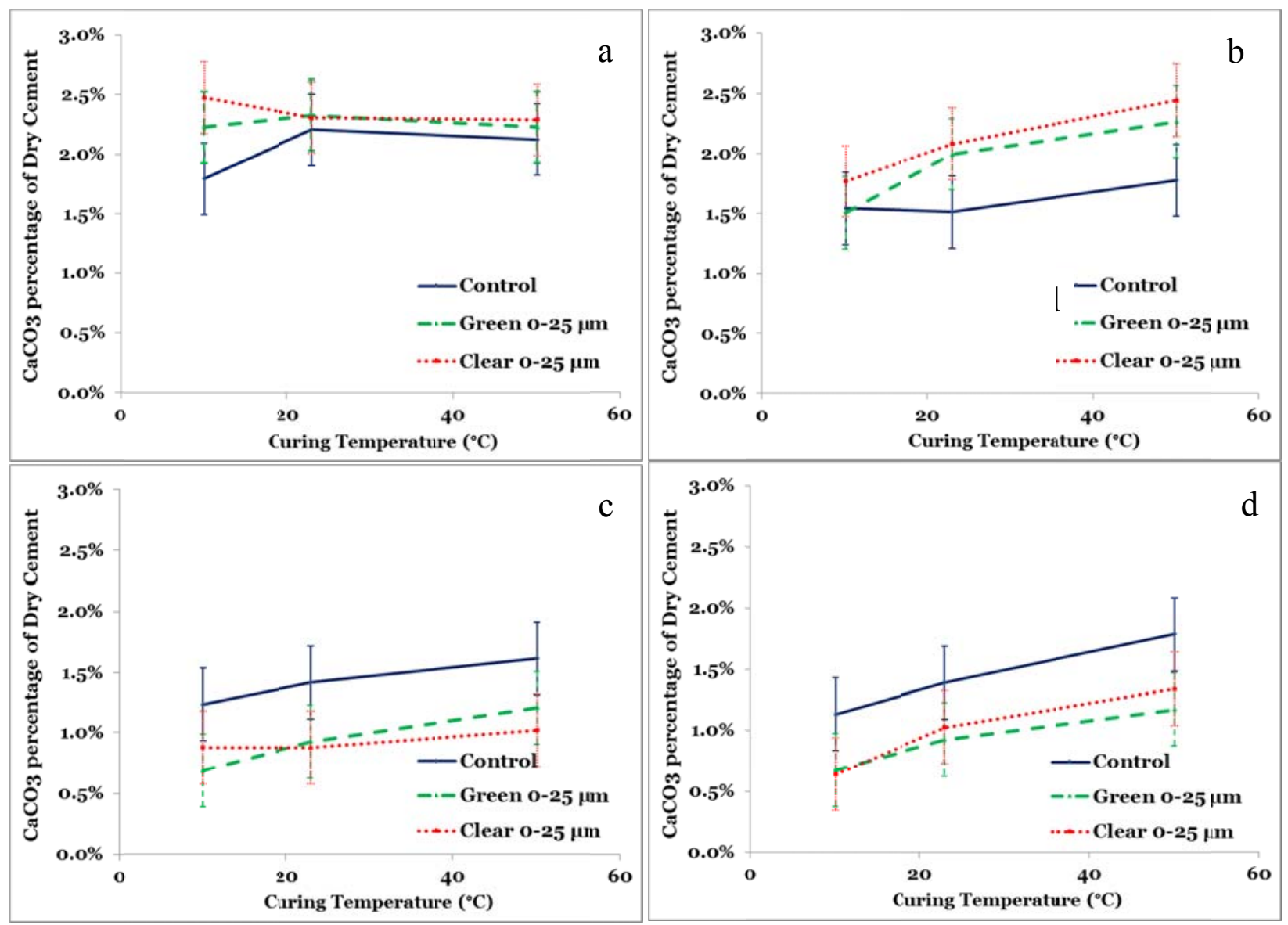

Figure 8. Calcium Carbonate content of paste samples; a. at 1 day, b. at 7 days, c. at 28 days, d. at 91 days

\subsection{Scanning Electron microscope (SEM)}

Figure 9 shows SEM images of paste sample containing clear glass powder at seven and 180 days. To investigate the effects of glass powder and curing temperatures on reactivity, relative density of inner C-S-H around cement grains was calculated. At seven days and $23^{\circ} \mathrm{C}$, inner C-S$\mathrm{H}$ relative density around the cement grain in paste samples containing green glass was 2.48 , while higher density was noted at seven days and $50^{\circ} \mathrm{C}$ (inner C-S-H density of 2.50 ), meaning hydration products are produced more significantly at elevated temperatures. At 180 days and $23^{\circ} \mathrm{C}$, the calculated density was 2.51 and at $50^{\circ} \mathrm{C}$ was 2.54 , reflecting that the $\mathrm{C}-\mathrm{S}-\mathrm{H}$ density at initial ages and lower curing temperatures is less than later ages and elevated temperatures; as density of C-S-H is increased while time passed and temperature is increased. 


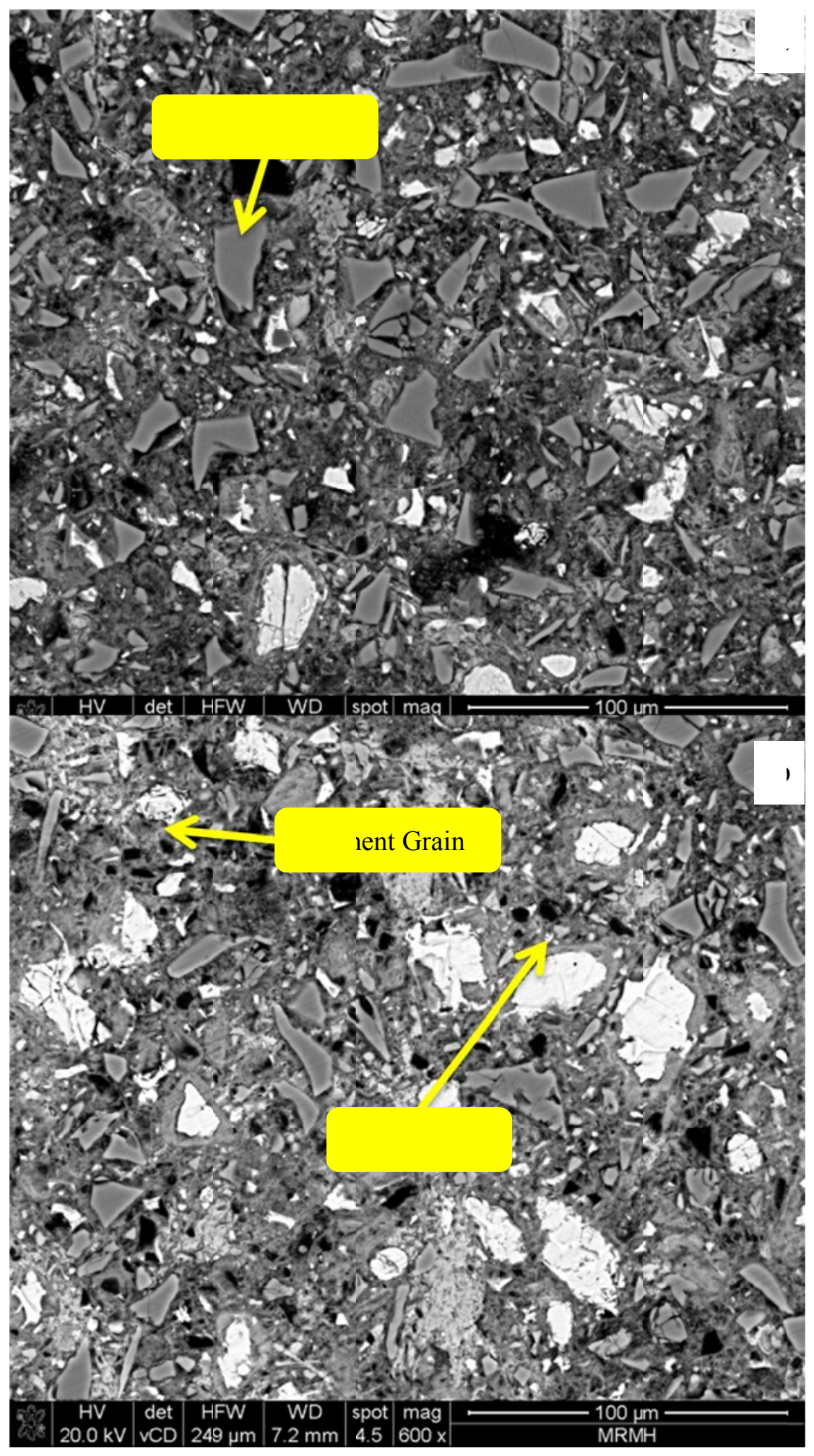



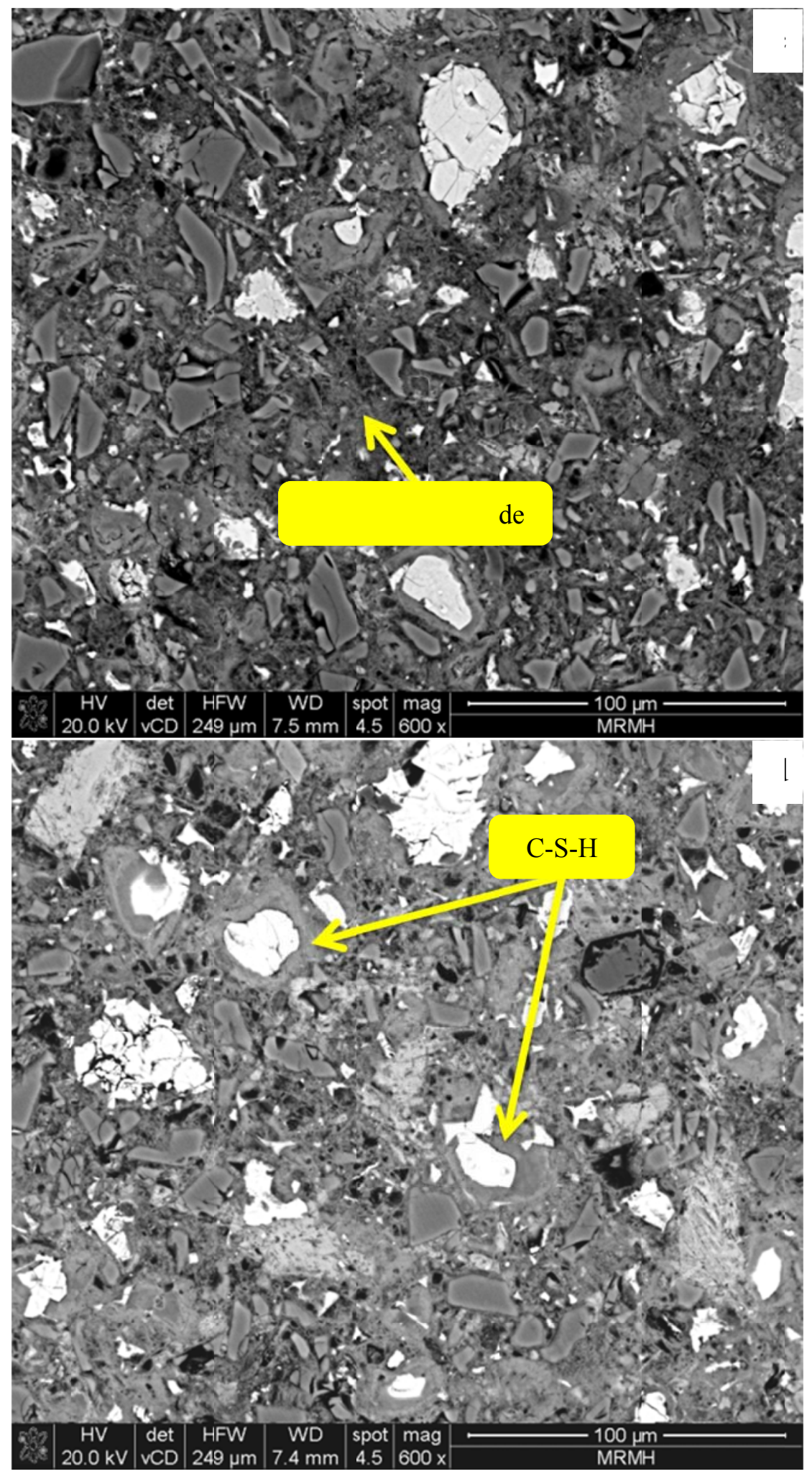

Figure 9. SEM Images of paste samples containing clear glass cullet; a. at $23^{\circ} \mathrm{C}$ at 7 days, b. at $50^{\circ} \mathrm{C}$ at 7 days, c. at $23^{\circ} \mathrm{C}$ at 180 days, $d$. at $50^{\circ} \mathrm{C}$ at 180 days 


\subsection{Compressive strength}

Evolution of compressive strength of mortar samples with and without $25 \%$ cement replacement by glass powder is illustrated in Figure 10. The control samples were seen to have higher strength than those containing glass powders at all curing ages tested up to 90 days and at $10^{\circ} \mathrm{C}$ and $23^{\circ} \mathrm{C}$. The lower strength of samples containing glass can be attributed to the increase in effective w/c ratio and from the lower glass reaction level at lower temperatures. However, as glass reaction increased at later ages, compressive strength of mortar increased and approached the strength of the control samples. At $50^{\circ} \mathrm{C}$ and after seven days, control and clear glass samples exhibited lower strength than green glass samples. After 28 days, clear glass showed some pozzolanic reaction, reflected by slightly higher compressive strength than control sample. Results indicate that green glass is significantly more reactive than clear glass because high $\mathrm{pH}$ cementitious matrix breaks down the silica structure of the glass and silica and aluminum could dissolve more and participate in the pozzolanic reaction. Higher silica and aluminum dissolution seen in the green glass during the bottle leaching experiment correlate to the higher pozzolanic reaction and lower $\mathrm{CH}$ and higher compressive strength. This is likely a result of change in the glass structure from the addition of coloring agent. Additionally, the effect of elevated temperature on strength gain is observed in Figure 10. At 28 days, neither clear nor green glass powders showed significant pozzolanic reaction. Although TGA results showed some pozzolanic reaction at $23^{\circ} \mathrm{C}$, that pozzolanic reaction was not enough to overcome a decrease in compressive strength at 28 days caused by the higher effective water-to-cement ratio. However, at $50^{\circ} \mathrm{C}$ compressive strength increased $30 \%$ at 28 days, which was in well agreement in TGA results. 


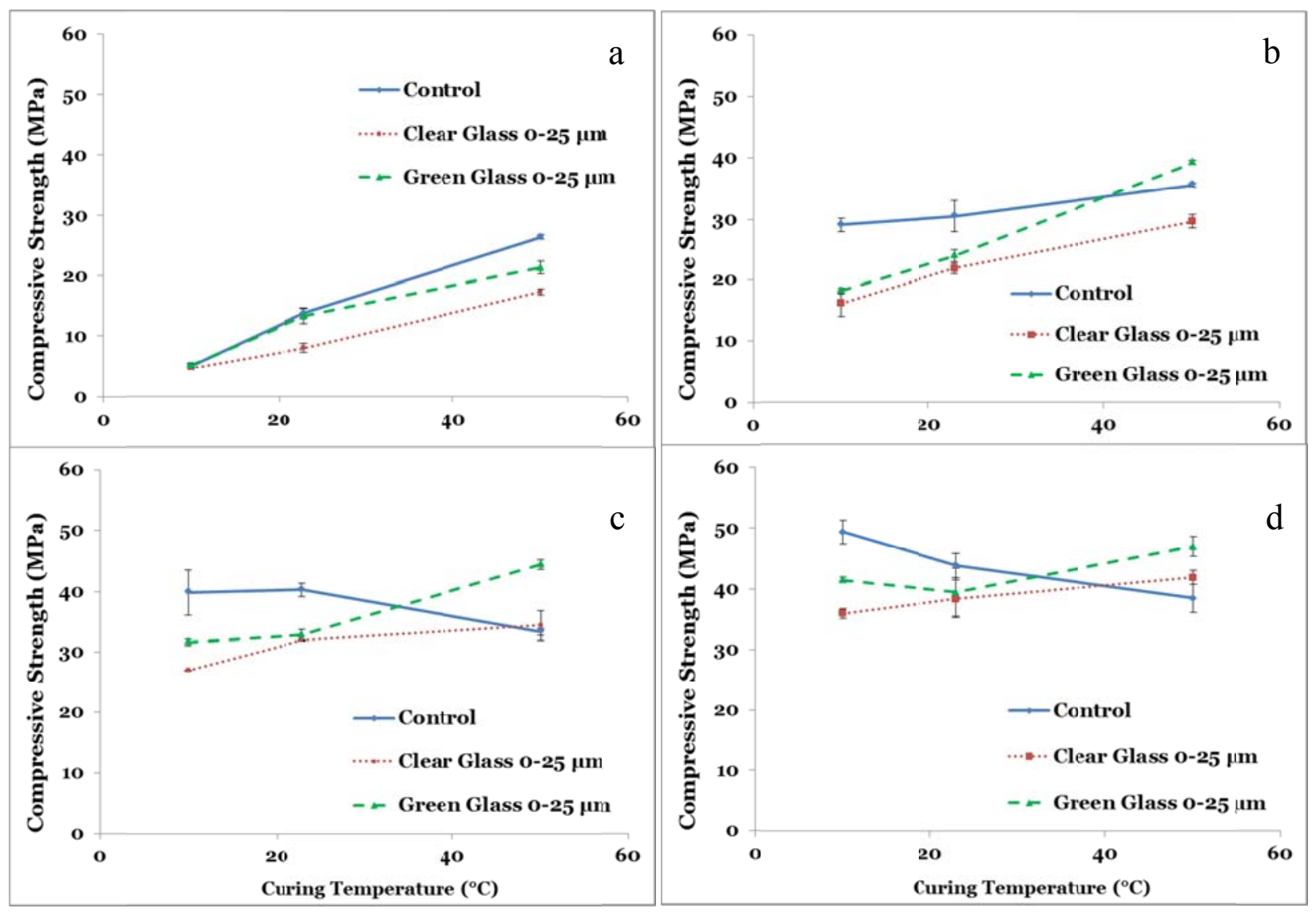

Figure 10. Compressive strength of mortar samples; a. at 1 day, b. at 7 days, c. at 28 days, d. at 91 days

\subsection{Water Sorptivity}

Figure 11 shows water sorptivity of mortar discs with and without glass powder. All samples had considerable absorption at early ages (i.e., one day), especially at $10^{\circ} \mathrm{C}$. At $50^{\circ} \mathrm{C}$, water absorption was reduced up to $30 \%$ because of accelerated hydration and the creation of more hydration product. This phenomenon indicates that at early ages, elevated temperatures decrease concrete porosity by producing denser hydration products, already observed in inner C-S-H relative density results from SEM images, especially, due to the existence of adequate space to accommodate quickly-formed hydration products. At later ages, water sorptivity of the control sample at $50^{\circ} \mathrm{C}$ was much higher than that at $10^{\circ} \mathrm{C}$ (cross-over effect). Although reaction products of control samples are denser at later ages at $50^{\circ} \mathrm{C}$, there is more porosity which is the 
reason for higher water sorptivity of control samples. On the other hand, glass cullet which reacts slower than the cement, is better able to fill in higher porosity from denser cement hydration products at later ages at elevated temperatures eliminating the cross-over effect as seen in Figure 11. An explanation may be because no additional space for hydration products existed (diffusion controlled stage) and the overall structure was already set. In addition, green glass is able to reduce water absorption to some extent more than clear glass, as green glass has a higher tendency to participate in the pozzolanic reaction.
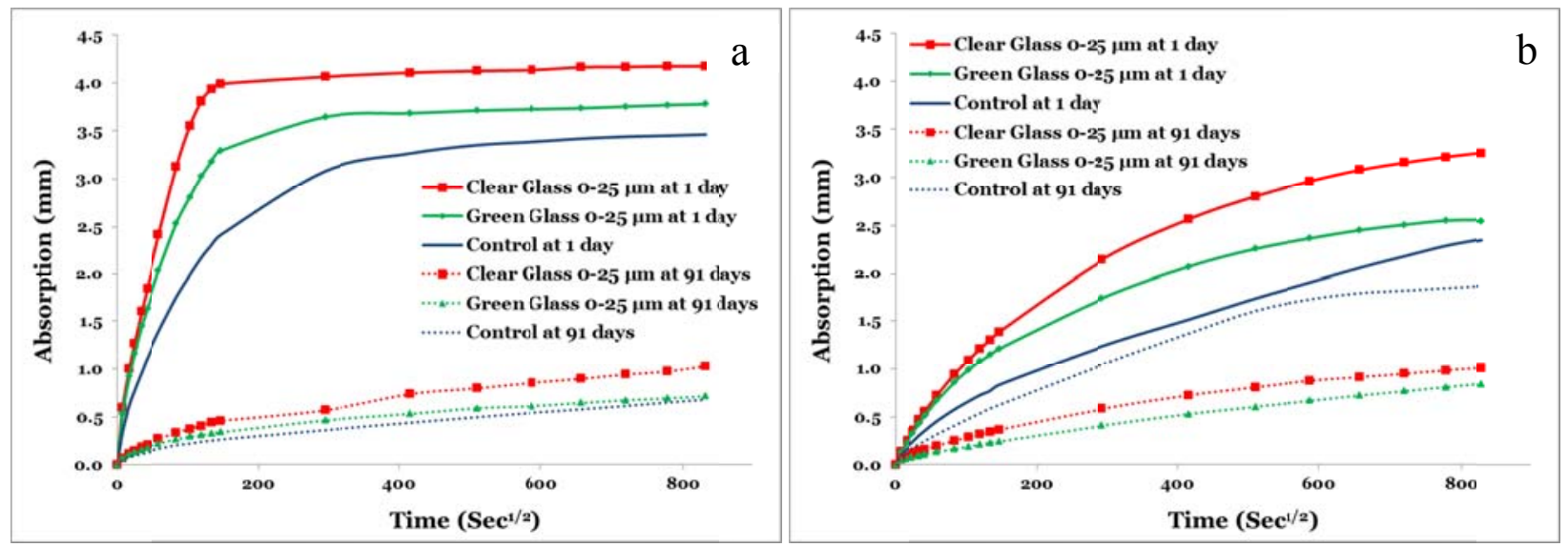

Figure 11. Water absorption of mortar samples; a. at $10^{\circ} \mathrm{C}, \mathrm{b} .50^{\circ} \mathrm{C}$

\section{Conclusion}

The current study investigated the effect of curing temperatures and the type of glass powder on pozzolanic reactivity of glass cullet in concrete. Based on experimental results, the following conclusions can be made:

1- At low temperature, finely ground glass (finer than $25 \mu \mathrm{m}$ ) does not show pozzolanic behavior. At $10^{\circ} \mathrm{C}$, no significant reduction in $\mathrm{CH}$ content was observed until 91 days. Additionally, mortar samples containing glass cullet have lower compressive strength and higher water sorptivity than control samples, even at 91 days. 
2- Finely ground glass cullet (finer than $25 \mu \mathrm{m}$ ) shows significant pozzolanic behavior at elevated temperatures (i.e. $50^{\circ} \mathrm{C}$ ). The reduction in $\mathrm{CH}$ content of samples containing glass with an increased heat of hydration at 1 day evidences this. At later ages - i.e. after seven days $-\mathrm{CH}$ content noticeably decreases, showing more pozzolanic reaction, which correlates well with results of SEM imaging, compressive strength, and water sorptivity tests.

3- Curing temperature is one of the foremost factors affecting pozzolanic behavior of glass cullet. The results of apparent activation energy calculation showed that glass especially green glass - is temperature sensitive and has a higher tendency to participate in pozzolanic reaction. This was also evidenced by TGA and compressive strength results.

4- Part of the reactivity at low temperatures can be attributed to calcium carbonate; as $\mathrm{AF}_{\mathrm{m}}$ phases containing calcium carbonate could react faster at lower temperatures, potentially giving a larger driving force for more dissolution of $\mathrm{CaCO}_{3}$.

5- At $\mathrm{pH}$ ranges similar to that seen in concrete (i.e. 12.5-13.5), aluminum content of green glass - which is 27 times higher than clear glass - and silica can more easily dissolve in pore solution, evidenced by bottle leaching test results, and may be the reason for the higher reactivity seen than clear glass.

\section{Acknowledgement}

Finances for this work have been provided by the National Science Foundation (CMMI1032636). The authors would like to appreciate Ash Grove Cement Company for performing chemical analysis and measuring surface area and density of materials. Discussion with Jeffrey Bullard is also appreciated. The help of all my assistants, especially Alaa Eldin Abouelleil, is gratefully acknowledged. 


\section{References}

[1] N. Schwarz, H. Cam, H., N. Neithalath, Influence of a Fine Glass Powder on the Durability Characteristics of Concrete and its Comparison to Fly Ash, Cement \& Concrete Composites, 30 (2008), 486-496.

[2] C. Meyer, Recycled Glass - From Waste Material to Valuable Resource, Proceedings of the International Syposium: Recycling and reuse of Glass Cullet, Dundee, Scotland, 2001, 1-10.

[3] Y. Shao, P. Lehoux, Feasibility of Using Ground Waste Glass as a Cementitious Material, Proceedings of the International Syposium: Recycling and reuse of Glass Cullet, Dundee, Scotland, 2001, 209-219.

[4] Y. Shao, T. Lefort, S. Moras, D. Rodriguez, Studies on Concrete Containing Ground Waste Glass, Cement and Concrete Research, 30(1) (2000), 91-100.

[5] T.D. Dyer, R.K. Dhir, Chemical Reactions of Glass Cullet Used as Cement Component, Journal of Material of Civil Engineering, 13(6) (2001), 412-417.

[6] A. Shayan, A. Xu, Value-added Utilization of Waste Glass in Concrete, Cement and Concrete Research, 34(1) (2004), 81-89.

[7] A. Shayan, A. Xu, Performance of Glass Powder as a Pozzolanic Material in Concrete: A Field Trial on Concrete Slabs, Cement and Concrete Research, 36(3) (2006), 457-468.

[8] L.A. Pereira-de-Oliveira, J.P. Castro-Gomes, P.M.S. Santos, The Potential Pozzolanic Activity of Glass and Red-clay Ceramic Waste as Cement Mortars Components, Construction and Building Material, 31 (2012), 197-203. 
[9] E.A. Byars, B. Morales-Hernandez, H.Y. Zhu, Waste Glass as Concrete Aggregate and Pozzolan, Concrete, 38(1) (2004), 41-44.

[10] R. Nassar, P. Soroushian, Field Investigation of Concrete Incorporating Milled waste Glass, Journal of Solid Waste Technology and Management, 37(4) (2011), 307-319.

[11] M.N. Bajad, C.D. Modhera, A.K. Desai, Effect of Glass on Strength of Concrete Subjected to Sulphate Attack, International Journal of Civil Engineering Research and Development, 1(2) (2011), 1-13.

[12] A. Meena, R. Singh, Comparative Study of Waste Glass Powder as Pozzolanic Material in Concrete, Bachelor Thesis, Department of Civil engineering, National Institute of Technology, Rourkela, India, 2012, 46 pp.

[13] S.C. Kou, F. Xing, The Effect of Recycled Glass Powder and Reject Fly ash on the Mechanical Properties of fiber-reinforced Ultralight Performance Concrete, Advances in Material science and Engineering, 2012, 8 pp.

[14] L. Federico, Waste Glass - A Supplementary Cementitious Material, Ph.D. Dissertation, Department of Civil engineering, McMaster University, Hamilton, Ontario, Canada, 2013, 99 pp.

[15] S.H. Kosmatka, B. Kerkhoff, W.C. Panarese, Design and Control of Concrete Mixtures, Portland Cement Association, $14^{\text {th }}$ Edition, 2003, USA, 360 pp.

[16] I. Elkhadiri, M. Palacios, F. Puertas, Effect of Curing Temperature on Cement Hydration, Ceramic-Silikaty, 53(2) (2009), 65-75. 
[17] A.R. Chini, L.C. Muszynski, L. Acquaye, L., and S. Tarkhan, Determination of Maximum Placement and Curing Temperatures in Mass Concrete to Avoid Durability Problems and DEF, Florida Department of Transportation, Final Report, 2003, 167 pp.

[18] P.K. Mehta, Global Concrete Industry Sustainability, Concrete International, 31(2) (2009), pp. $45-48$.

[19] J.C. Russ, Practical Stereology, Springer, 1986, 196 pp.

[20] J.L. Poole, K.A. Riding, K.J. Folliard, M.C. Juenger, A.K. Schindler, Methods for Calculating Activation Energy for Portland Cement, ACI Materials Journal, 104(1) (2007), 303-311.

[21] L. D'Aloia, G. Chanvillard, Determining the "apparent" activation energy of concrete: $E_{a}-$ Numerical simulations of the heat of hydration of cement, Cement and Concrete Research, 32(8) (2002), 1277-1289.

[22] ASTM, Chemical Shrinkage of Hydraulic Cement Paste, ASTM C 1608, 2012, 5 pp.

[23] S. Sarkar, A. Halder, S. Bishnoi, Shrinkage in concretes containing fly ash, UKIERI Concrete Congress, Jalandhar, India, 2013.

[24] B.K. Marsh, Relationships between engineering properties and microstructure characteristics of hardened cement paste containing pulverized fuel ash as a partial cement replacement, PhD thesis, The Hatfield Polytechnic, UK, 1984.

[25] S. Bishnoi, K. Scrivener, $\mu$ ic: A new platform for modelling the hydration of cements, Cement and Concrete Research, 39(4) (2009), 266-274. 
[26] S. Bishnoi, Vector Modelling of Hydrating Cement Microstructure and Kinetics, Doctoral Thesis, Swiss Federal Institute of Technology in Lausanne, Laboratory of Materials of Construction, 2008, 166 pp.

[27] X. Zhang, Quantitative Microstructural Characterization of Concrete Cured Under Realistic Temperature Conditions, Doctoral Thesis, Swiss Federal Institute of Technology at Lausanne, 2007, 282 pp.

[28] ASTM,. Standard Test Method for Compressive Strength of Hydraulic Cement Mortars (Using 2-in. or [50-mm] Cube Specimens), ASTM C 109M, 2012, 10 pp.

[29] C. Shi, Y. Wu, C. Riefler, H. Wang, Characteristics and Pozzolanic Reactivity of Glass Powders, Cement and Concrete Research, 35(5) (2005), 987-993.

[30] ASTM, Measurement of Rate of Absorption of Water by Hydraulic Cement Concretes, ASTM C 1585, 2011, 6 pp.

[31] W.B. White, Theory of Corrosion of Glass and Ceramics, In: D.E. Clarke and B.K. Zoitos editors, Corrosion of glass, ceramics and superconductors. Park Ridge, NJ, (1992), 2-28. 